\title{
Quality of reporting and risk of bias in therapeutic otolaryngology publications
}

\author{
N M KAPER ${ }^{1}$, K M A SWART ${ }^{1}$, W GROLMAN ${ }^{1}$, G J M G VAN DER HEIJDEN ${ }^{1,2}$ \\ ${ }^{1}$ Department of Otorhinolaryngology and Head and Neck Surgery, Brain Center Rudolf Magnus, University \\ Medical Center Utrecht, and ${ }^{2}$ Department of Social Dentistry, Academic Center for Dentistry Amsterdam, \\ University of Amsterdam and Vrije Universiteit Amsterdam, The Netherlands
}

\begin{abstract}
Background: High-quality trials have the potential to influence clinical practice.

Methods: Ten otolaryngology journals with the highest 2011 impact factors were selected and publications from 2010 were extracted. From all medical journals, the 20 highest impact factor journals were selected, and publications related to otolaryngology for 2010 and 2011 were extracted. For all publications, the reporting quality and risk of bias were assessed.

Results: The impact factor was 1.8-2.8 for otolaryngology journals and 6.0-101.8 for medical journals. Of 1500 otolaryngology journal articles, 262 were therapeutic studies; 94 had a high reporting quality and 5 a low risk of bias. Of 10967 medical journal articles, 76 were therapeutic studies; 57 had a high reporting quality and 8 a low risk of bias.

Conclusion: Reporting quality was high for 45 per cent of otolaryngology-related publications and 9 per cent met quality standards. General journals had higher impact factors than otolaryngology journals. Reporting quality was higher and risk of bias lower in general journals than in otolaryngology journals. Nevertheless, 76 per cent of articles in high impact factor journals carried a high risk of bias. Better reported and designed studies are the goal, with less risk of bias, especially in otolaryngology journals.
\end{abstract}

Key words: Evidence-Based Medicine; Bias; Methodology; Journal Impact Factor

\section{Introduction}

In order to provide high-quality healthcare, clinicians are expected to have knowledge of the best available research evidence conducted in their field. They should be able to combine this knowledge with their experience and their patient's wishes when making clinical decisions, which is an approach known as evidence-based practice. ${ }^{1}$ This means that clinicians should be able to find and select publications that are relevant for clinical practice and which have sufficient methodological quality. ${ }^{2,3}$

There is a large quantity of publications in otolaryngology, of which a major proportion is thought to lack clinical relevance or be of insufficient quality. ${ }^{4}$ High-quality research is important because it can change clinical practice, foster patient experiences and improve healthcare benefits.

This study aimed to assess the quality of methods in otolaryngological studies. As most studies published concern the evaluation of treatment effects, and the assessment tools for such intervention studies are well established and accepted, we focused on the quality of such study publications. ${ }^{5}$ The quality of a study depends largely on the quality of reporting and the risk of bias of the applied study design. Without adequate reporting, risk of bias cannot be assessed. ${ }^{6}$ General standards and conditions for reporting intervention studies and avoiding risk of bias are widely known and available. ${ }^{7,8}$

Clinicians rely, among other things, on impact factor to select the best available evidence. The impact factor is widely assumed to be an indicator of the quality of research journals. ${ }^{9}$ It is calculated at the end of every year, based on the number of citations in the previous two-year period, relative to the number of publications in this period. ${ }^{10}$ Researchers strive to publish in journals with the highest impact factor. Consequently, these journals are seen as the leading and most prestigious journals. ${ }^{11,12}$

For our study, we selected the leading field-specific and general medical journals. We extracted publications on treatment outcomes in otolaryngology, and we investigated their quality of reporting and risk of bias. We compared the findings based on the 
publication source, either selected otolaryngology journals or selected general medical journals. We expected to find a major portion of high-quality otolaryngology publications in the selected general medical journals.

\section{Materials and methods}

\section{Publication search and classification}

We defined our cohort of publications in the year 2012. Using the most recent impact factors, from 2011, we selected 10 otolaryngology journals with the highest impact factor and searched for citable articles (i.e. peer-reviewed publications) from $2010 .{ }^{13}$ We ranked all medical journals in the 2011 Journal Citation Report ${ }^{13}$ by their impact factor and selected 20 with the highest impact factor that were likely to publish otolaryngology-related research. We selected journals with a subspecialty related to otolaryngology (e.g. oncology, allergy, respiratory) and journals that transcend multiple disciplines (e.g. The Lancet, The BMJ, PLOS Medicine). Two authors (NK and KS) independently selected journals and searched for otolaryngology-related publications; initial disagreement was resolved by discussion until agreement was reached. We selected journals from both 2010 and 2011, because we expected to find few articles and aimed to include a sufficient number of studies to compare between journals.

Two authors (NK and KS) independently retrieved and reviewed all publications. We selected studies reporting first-hand and original data, conducted on living patients. We selected only clinical research, with a determinant and outcome relevant for patient care. We searched for therapeutic studies; that is, studies estimating the effect of an intervention on the course and outcome of a disease. We included all therapeutic intervention studies, both randomised and non-randomised studies, multiple and single group comparisons, and prospective and retrospective trials. Studies reporting on less than 10 patients were excluded. ${ }^{14}$ Initial disagreement on the selection and categorisation of articles was discussed with a third author (GH) until agreement was reached; the selection is therefore based on a full consensus.

\section{Publication quality assessment}

Based on pre-defined criteria, we evaluated the quality of selected articles by their study design. Assessment involved the evaluation of: selection bias, notably the study design characteristic of treatment assignment by (1) random and (2) concealed allocation; information bias, notably standardisation of (3) treatments and (4) outcome assessments; performance bias, (5) blinding of outcome assessment, and attrition bias; and (6) completeness of reported data (Table I). ${ }^{14,15}$ The Cochrane Handbook includes criteria 1, 2, 5 and 6 in their assessment of bias. ${ }^{16}$

When item information was not provided or not clearly reported, we rated it as insufficient. When item information was clearly reported, it was rated as sufficient. Studies were assigned a high reporting quality for reporting five or six items, a moderate reporting quality for reporting three or four items, and a low reporting quality for reporting zero, one or two items. For the classification, it did not matter which item was fulfilled: all items were assigned an equal weight.

After determining reporting quality, we assessed risk of bias per item. When the reporting allowed assessment (i.e. when reporting was rated sufficient), we rated the item as either satisfied or not satisfied. When the reporting quality was insufficient, the item was rated as not satisfied. Two authors (NK and KS) independently assessed articles and resolved initial disagreements by discussion.

Because selection bias is most important in therapeutic studies, these items were assigned most weight in terms of risk of bias. ${ }^{15}$ Studies that did not satisfy criteria 1 and 2 (random and concealed allocation) were considered to have a high risk of bias, even if they fulfilled all other items. Studies were classified as having a low risk of bias if they satisfied criteria 1 and 2 plus all other study design features. If studies satisfied criteria 1 and 2 but failed on one or two of the other

TABLE I

CHECKLIST ITEMS FOR ASSESSMENT OF THERAPEUTIC PUBLICATIONS

\begin{tabular}{ll}
\hline Checklist item & \multicolumn{1}{c}{ Description } \\
\hline $\begin{array}{l}\text { Random allocation } \\
\text { Concealed allocation }\end{array}$ & $\begin{array}{l}\text { Independent set procedure to generate random allocation } \\
\text { Treatment allocation was independent from selection (e.g. central allocation, like telephone service or } \\
\text { web-based) } \\
\text { Protocolled, uniform treatment \& co-treatment (including placebo) }\end{array}$ \\
$\begin{array}{l}\text { Standardisation of treatments } \\
\text { Standardisation of outcome } \\
\text { assessments }\end{array}$ & $\begin{array}{l}\text { Protocolled, uniform measurement \& assessment of outcome } \\
\text { Blinding of outcome assessment }\end{array}$ \\
$\begin{array}{l}\text { Outcome is measured, obtained \& documented without knowledge of the treatment; observers of } \\
\text { outcome are blinded to treatment (by blinding or placebo) } \\
\text { Completeness of reported data } \\
\text { documented, preferably displayed in flow chart } \\
\text { Number of patients included are reported, for all treatment groups, with a description of source } \\
\text { population \& reasons for participant exclusion } \\
\text { Number of patients is analysed per treatment group; loss to follow up should be } \leq 20 \%\end{array}$ \\
\hline
\end{tabular}


four features, they were rated as having a moderate risk of bias. Studies that failed on more items were classified as having a high risk of bias.

According to current quality standards, studies should have good reporting quality, and moderate or low risk of bias. ${ }^{17}$

\section{Data analysis}

We entered and analysed data using SPSS statistical software, version 23.0 (Chicago, Illinois, USA). We compared ordinal outcomes using the Mann-Whitney $\mathrm{U}$ test. Binary outcomes were tested using the chisquare test. We used a Bonferroni post-hoc correction to determine inflated risks of a type 1 error in cases of multiple testing. For prediction of outcomes, ordinal logistic regression was performed.

\section{Results}

The 10 selected otolaryngology journals had impact factors ranging from 1.8 to 2.8 . The 20 selected medical journals had impact factors ranging from 6.0 to 101.8. For details on the selected journals and their impact factors, see Appendix 1.

Of 1500 citable articles in the otolaryngology journals, we identified 262 (17 per cent) therapeutic articles. Of these, 94 (36 per cent) had a high reporting quality (Table II); 7 (3 per cent) had a moderate risk of bias and 5 ( 2 per cent) had a low risk of bias (Table III).

Of 10967 citable articles in the selected medical journals, 183 (2 per cent) were original clinical studies related to otolaryngology. We identified 76 (42 per cent) therapeutic studies, 36 from 2010 and 40 from 2011. There were no statistical differences between the two years. Overall, 57 (75 per cent) had a high reporting quality (Table II); 10 (13 per cent) a moderate risk of bias and 8 (11 per cent) had a low risk of bias (Table III).

The results per checklist item are reported in Table IV. For the selected medical journals, only blinding was remarkably poorly reported. For the otolaryngology journals, both blinding and completeness of data were remarkably poorly reported. Other items were moderately to well reported. Risk of bias items were more often rated sufficient for publications in the selected medical journals. Randomisation, concealed allocation and blinding often had a low score, which explains the overall high risk of bias.

Table $\mathrm{V}$ shows the results of reporting quality against risk of bias. For a low or moderate reporting quality, the probability of low or moderate risk of bias was 0 . High reporting quality was therefore a pre-requisite in order to even qualify for a low or moderate risk of bias.

The results per journal are shown in Figure 1 (reporting quality) and Figure 2 (risk of bias). The details can be found in Appendix 2. From the 10 selected otolaryngology journals, 1 journal did not publish original research. The top three otolaryngology journals published little clinical research (their focus is on fundamental research); the number one otolaryngology journal did not publish any therapeutic studies (Appendix 2).

\section{Discussion}

Otolaryngology journals have a relatively low impact factor compared to the selected medical journals. Overall, the reporting standards were met for 45 per cent of therapeutic otolaryngology publications, and 9 per cent met our quality standards (having a low or moderate risk of bias). This is the first time such a study has been carried out in otolaryngology.

As a result of our selection approach, we missed publications, but there is unlikely to be high-quality otolaryngology research published outside of our selected journals. For efficiency, we selected studies from 2010, and assumed that our sample from 2010 would be representative of the studies published in the previous and subsequent year. We therefore presume that including more studies from adjacent years would lead to a reduction in random error, but would not change the outcome of our study. We included studies from the year 2010 because we expected to find more articles available in full text. Publications from 2010 (and even from before that) are still widely used in daily practice and guidelines. This is because it usually takes several years before publications are used in daily practice. ${ }^{18}$

We could have introduced bias in our study because the authors and journals that published the studies we assessed were not blinded. Therefore, the researchers who evaluated the quality of the articles could have been influenced by its authors or by the impact factor

TABLE II

OVERALL REPORTING QUALITY

\begin{tabular}{|c|c|c|c|c|c|}
\hline \multirow[t]{2}{*}{ Journal type } & \multirow[t]{2}{*}{ Articles $(n)$} & \multicolumn{3}{|c|}{ Reporting quality } & \multirow[t]{2}{*}{$P$-value* } \\
\hline & & $\operatorname{High}(n(\%))$ & Moderate $(n(\%))$ & Low $(n(\%))$ & \\
\hline Selected medical journals & 76 & $57(75)$ & $19(25)$ & $0(0)$ & $<0.05$ \\
\hline Otolaryngology journals & 262 & $94(36)$ & $165(63)$ & $3(1)$ & \\
\hline Total & 338 & $151(45)$ & $184(54)$ & $3(1)$ & \\
\hline
\end{tabular}

${ }^{*}$ Overall significance calculated using a Mann-Whitney U test. Post-hoc tests with a Bonferroni correction showed a significant difference between the moderate and high categories. 


\begin{tabular}{|c|c|c|c|c|c|}
\hline & & $\begin{array}{r}\text { TABL } \\
\text { DVERALL RI }\end{array}$ & BIAS & & \\
\hline Journal type & Articles $(n)$ & & Risk of bias & & $P$-value* \\
\hline & & Low $(n(\%))$ & Moderate $(n(\%))$ & $\operatorname{High}(n(\%))$ & \\
\hline Selected medical journals & 76 & $8(11)$ & $10(13)$ & $58(76)$ & $<0.05$ \\
\hline Otolaryngology journals & 262 & $5(2)$ & $7(3)$ & $250(95)$ & \\
\hline Total & 338 & $13(4)$ & $17(5)$ & $308(91)$ & \\
\hline
\end{tabular}

*Overall significance calculated using a Mann-Whitney U test. Post-hoc tests with a Bonferroni correction showed significant differences between the low and high and between the moderate and high categories.

\begin{tabular}{|c|c|c|c|c|}
\hline \multirow{3}{*}{ Item } & \multicolumn{3}{|c|}{$\begin{array}{l}\text { TABLE IV } \\
\text { RTING QUALITY AND RISK OF BIAS PER CHECKLIST ITEM }\end{array}$} & REPORTING QUALITY AND RISK OF BIAS PER CHECKLIST ITEM \\
\hline & \multicolumn{2}{|c|}{ Reporting quality } & \multicolumn{2}{|c|}{ Risk of bias } \\
\hline & Articles $\left(n^{*}(\%)\right)$ & OR $(95 \% \mathrm{CI})^{\dagger}$ & $\operatorname{Articles}\left(n^{\ddagger}(\%)\right)$ & OR $(95 \% \mathrm{CI})^{\dagger}$ \\
\hline \multicolumn{5}{|l|}{ Random allocation } \\
\hline - Otolaryngology journals & $251(96)$ & $0.2(0.1-0.5)$ & $19(7)$ & $5.9(3.0-11.6)$ \\
\hline - Selected medical journals & $63(83)$ & & $24(32)$ & \\
\hline \multicolumn{5}{|l|}{ Concealed allocation } \\
\hline $\begin{array}{l}\text { - Otolaryngology journals } \\
\text { - Selected medical journals }\end{array}$ & $\begin{array}{r}240(92) \\
60(79)\end{array}$ & $0.3(0.2-0.7)$ & $\begin{array}{l}11(4) \\
21(28)\end{array}$ & $8.7(4.0-19.1)$ \\
\hline \multicolumn{5}{|l|}{ Standardisation of treatment } \\
\hline $\begin{array}{l}\text { - Otolaryngology journals } \\
\text { - Selected medical journals }\end{array}$ & $\begin{array}{r}209(80) \\
70(92)\end{array}$ & $3.0(1.2-7.2)$ & $\begin{array}{r}122(47) \\
60(79)\end{array}$ & $4.3(2.4-7.9)$ \\
\hline \multicolumn{5}{|l|}{ Standardisation of outcome } \\
\hline - Otolaryngology journals & $211(81)$ & $8.9(2.1-37.7)$ & $193(74)$ & $13.2(3.2-55.3)$ \\
\hline - Selected medical journals & $74(97)$ & & $74(97)$ & \\
\hline \multicolumn{5}{|l|}{ Blinding of outcome } \\
\hline - Otolaryngology journals & $27(10)$ & $7.0(3.9-12.9)$ & $20(8)$ & $4.3(2.2-8.5)$ \\
\hline - Selected medical journals & $34(45)$ & & $20(26)$ & \\
\hline \multicolumn{5}{|l|}{ Completeness of data } \\
\hline - Otolaryngology journals & $141(54)$ & $12.2(4.8-31.2)$ & $104(40)$ & $5.3(3.0-9.5)$ \\
\hline - Selected medical journals & $71(93)$ & & $59(78)$ & \\
\hline
\end{tabular}

${ }^{*}$ Number of articles that adequately reported the item. ${ }^{\dagger}$ Calculated using the chi-square test. ${ }^{\dagger}$ Number of articles that were rated sufficient. $\mathrm{OR}=$ odds ratio $\mathrm{CI}=$ confidence interval

of the journal it was published in. However, by performing a systematic evaluation, which was executed independently by two authors, we reduced this risk of bias.
In evaluating the quality of publications, we limited the methodological aspects assessed, to provide an overview of the results. Adding items to the current classification would not change the risk of bias, but it

\begin{tabular}{|c|c|c|c|c|}
\hline \multicolumn{5}{|c|}{$\begin{array}{c}\text { TABLE V } \\
\text { EPORTING QUALITY AGAINST RISK OF BIAS }\end{array}$} \\
\hline \multirow[t]{2}{*}{ Reporting quality } & \multicolumn{3}{|c|}{ Risk of bias } & \multirow[b]{2}{*}{ Total } \\
\hline & Low & Moderate & High & \\
\hline \multicolumn{5}{|l|}{ High } \\
\hline - Otolaryngology journals & $5(2)$ & $6(2)$ & $83(32)$ & $94(36)$ \\
\hline - Selected medical journals & $8(11)$ & $10(13)$ & $39(51)$ & $57(75)$ \\
\hline - Category probability* (\%) & 8 & 11 & 81 & \\
\hline \multicolumn{5}{|l|}{ Moderate } \\
\hline - Otolaryngology journals & $0(0)$ & $1(0)$ & $164(63)$ & $165(63)$ \\
\hline - Selected medical journals & $0(0)$ & $0(0)$ & $19(25)$ & $19(25)$ \\
\hline - Category probability* (\%) & 0 & 0 & 100 & \\
\hline \multicolumn{5}{|l|}{ Low } \\
\hline - Otolaryngology journals & $0(0)$ & $0(0)$ & $3(1)$ & $3(1)$ \\
\hline - Selected medical journals & $0(0)$ & $0(0)$ & $0(0)$ & $0(0)$ \\
\hline - Category probability* (\%) & 0 & 0 & 100 & \\
\hline \multicolumn{5}{|l|}{ Total } \\
\hline - Otolaryngology journals & $5(2)$ & $7(3)$ & $250(95)$ & $262(100)$ \\
\hline - Selected medical journals & $8(11)$ & $10(13)$ & $58(76)$ & $76(100)$ \\
\hline
\end{tabular}

Data represent numbers and percentages of articles, unless indicated otherwise. ${ }^{*}$ Probabilities calculated by an ordinal regression model, with $p<0.05$ for fitting of the model (Nagelkerke's $\mathrm{R}^{2}=0.23$, goodness of fit test $p>0.05$ and test of parallel lines $p=0.61$ ). 


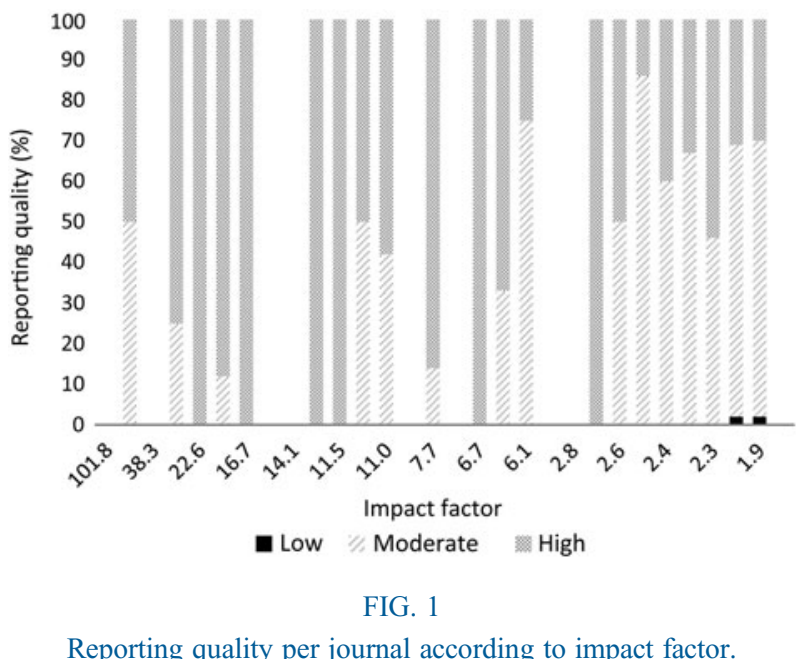

could have an effect on the reporting quality. We believe we chose valid items for our rating, as all are derived from the Cochrane Handbook. We did not include the selective reporting item because we did not compare outcomes between different studies. ${ }^{16}$

There are important differences between otolaryngology journals and the selected medical journals. Our results show that the selected medical journals, which have a high impact factor, have better reporting quality and published considerably higher quality research. However, 76 per cent of the publications in these journals still had a high risk of bias, so a high impact factor is definitely not a guarantee of high quality. It was not possible to compare impact factors between journals, given the small differences in impact factor and the limited number of publications; nevertheless, Figures 1 and 2 show that there is variation between journals.

There are several explanations for the higher quality of publications in the selected medical journals. Medical journals can select from different research fields and are more attractive for authors to submit their research to, given their high impact factor. ${ }^{12}$ As

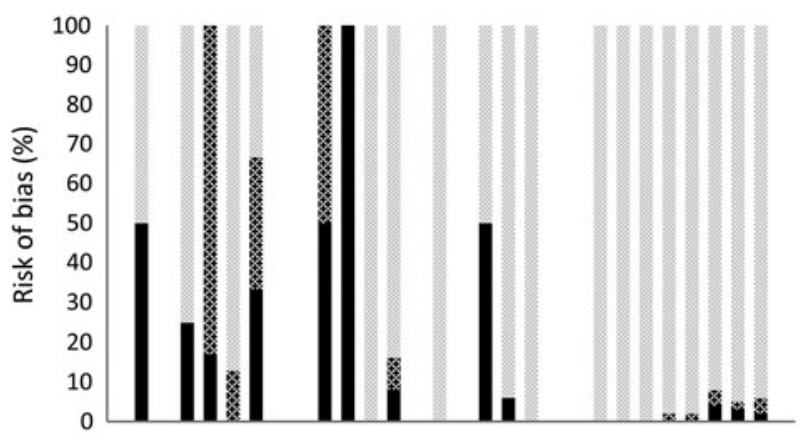

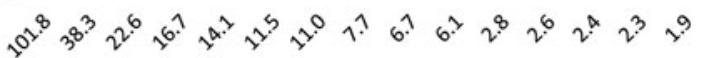

Impact factor

- Low s Moderate High

FIG. 2

Risk of bias per journal according to impact factor. a result, general medical journals have the first and most comprehensive choice when selecting publications. Additionally, high impact factor journals have stricter rules about reporting, and often authors are requested to fulfil checklists (such as the Consolidated Standards of Reporting Trials ('CONSORT')).

Our study provides important information for both research and clinical practice. The results show that the reporting of study designs needs to improve, especially for the lower impact factor otolaryngology journals. Even if not all items for risk of bias can be met, the reporting quality can and should always be high. In order to achieve improvement and help reduce research waste, there is a significant role for authors, reviewers and journals to play. ${ }^{4}$ Better reporting of studies and improved methodological quality is warranted. Furthermore, researchers, reviewers and editors can play an important role.

In the context of clinical practice, it is important for medical doctors to realise that they should always critically assess an article, even if it is published in a high impact factor journal. It is also important to be aware that relevant otolaryngology articles are not only published in otolaryngology journals, but also in general medical journals.

- For good medical practice, it is important that studies of sufficient quality are published

- The majority of otolaryngology papers do not meet current quality standards

- General medical journals have a considerably higher impact factor and publish more research of higher quality

- Overall, the goal should be better reported and designed otolaryngological studies

Publications should meet other conditions, besides those concerning reporting and methodological quality. Studies should preferably report original data, and should not simply review or summarise existing data, or express opinions. The study should be relevant and innovative; that is, the outcome should preferably have an impact on current policy. The journal or publication should be open access; furthermore, publishing studies driven by publication rates ('bean counting'), rather than by the above factors, must be avoided. ${ }^{4,12}$

\section{Conclusion}

The majority of therapeutic research in leading otolaryngology journals does not meet current standards for methodological quality. Selected medical journals, with a considerably higher journal impact factor, tend to publish research of higher quality. Nevertheless, almost half of their publications are of low quality. Both researchers and medical publishers have a responsibility to improve the quality of methods and reporting. Medical doctors should critically assess 
publications before applying their findings in daily practice, and should look outside their specialised literature when searching for high-quality evidence in their field.

\section{References}

1 Dawes M, Summerskill W, Glasziou P, Cartabellotta A, Martin $\mathrm{J}$, Hopayian K et al. Sicily statement on evidence-based practice. BMC Med Educ 2005;5:1

2 Grol R, Grimshaw J. From best evidence to best practice: effective implementation of change in patients' care. Lancet 2003; 362:1225-30

3 Burton MJ. Evidence-based medicine and otolaryngology-HNS: passing fashion or permanent solution. Otolaryngol Head Neck Surg 2007;137:47-51S

4 Ioannidis JP, Greenland S, Hlatky MA, Khoury MJ, MacLeod MR, Moher D et al. Increasing value and reducing waste in research design, conduct, and analysis. Lancet 2014;383:166-75

5 Shin JJ, Rauch SD, Wasserman J, Coblens O, Randolph GW. Evidence-based medicine in otolaryngology, part 2: the current state of affairs. Otolaryngol Head Neck Surg 2011;144:331-6

6 Turner L, Shamseer L, Altman DG, Schulz KF, Moher D. Does use of the CONSORT Statement impact the completeness of reporting of randomised controlled trials published in medical journals? A Cochrane review. Syst Rev 2012;1:60

7 The CONSORT statement. In: http://www.consort-statement. org [11 August 2016]
8 STROBE statement. In: http://www.strobe-statement.org [11 August 2016]

9 Brody S. Impact factor is the best operational measure for medical journals. Lancet 1995;346:1300-1

10 The Clarivate Analytics Impact Factor. In: https://clarivate. com/essays/impact-factor/ [11 August 2016]

11 Seglen PO. Why the impact factor of journals should not be used for evaluating research. BMJ 1997:314:498-502

12 Science in Transition. In: http://scienceintransition.nl/overscience-in-transition/position-paper [11 August 2016]

13 Journal Citation Report 2011. In: https://clarivate.com/products/journal-citation-reports / [6 November 2017]

14 McMaster University - HiRU's Approach to Search Filter Development. In: https://hiru.mcmaster.ca/hiru/HiRU_approach. pdf [11 August 2016]

15 Grobbee DE, Hoes AW. Clinical Epidemiology: Principles, Methods, and Applications for Clinical Research. London: Jones and Bartlett Publishers, 2009

16 Higgins JP, Green S, eds. Cochrane Handbook for Systematic Reviews of Interventions, Version 5.1.0 (updated March 2011). London: Cochrane Collaboration, 2011

17 Higgins JP, Altman DG, Sterne JA. Chapter 8: Assessing risk of bias in included studies. In: Higgins JP, Green S, eds. Cochrane Handbook for Systematic Reviews of Interventions, Version 5.1.0 (updated March 2011). London: Cochrane Collaboration, 2011

18 Glasziou P, Haynes B. The paths from research to improved health outcomes. ACP J Club 2005;142:A8-10

\section{Appendix 1 Impact factors (2011) for selected journals}

\begin{tabular}{|c|c|}
\hline Journals & Impact factor \\
\hline \multicolumn{2}{|l|}{ Medical journals } \\
\hline - CA: A Cancer Journal for Clinicians & 101.8 \\
\hline - The New England Journal of Medicine & 53.3 \\
\hline - The Lancet & 38.3 \\
\hline - JAMA: The Journal of the American Medical Association & 30.1 \\
\hline - The Lancet Oncology & 22.6 \\
\hline - Journal of Clinical Oncology & 18.4 \\
\hline - Annals of Internal Medicine & 16.7 \\
\hline - PLOS Medicine & 16.3 \\
\hline - The BMJ & 14.1 \\
\hline - Journal of the National Cancer Institute & 13.8 \\
\hline - JAMA Internal Medicine & 11.5 \\
\hline - American Journal of Respiratory and Critical Care Medicine & 11.1 \\
\hline - Journal of Allergy and Clinical Immunology & 11.0 \\
\hline - Canadian Medical Association Journal & 8.2 \\
\hline - Clinical Cancer Research & 7.7 \\
\hline - Annals of Surgery & 7.5 \\
\hline - The American Journal of Clinical Nutrition & 6.7 \\
\hline - Annals of Oncology & 6.4 \\
\hline - Allergy & 6.1 \\
\hline - BMC Medicine & 6.0 \\
\hline \multicolumn{2}{|l|}{ Otolaryngology journals } \\
\hline - Journal of the Association for Research in Otolaryngology & 2.8 \\
\hline the & 2.7 \\
\hline - Ear and Hearing & 2.6 \\
\hline - Audiology and Neurotology & 2.5 \\
\hline - Head \& Neck & 2.4 \\
\hline - Clinical Otolaryngology & 2.4 \\
\hline - The American Journal of Rhinology \& Allergy & 2.3 \\
\hline - The Laryngoscope & 2.0 \\
\hline - Otology \& Neurotology & 1.9 \\
\hline - Current Opinion in Otolaryngology \& Head \& Neck Surgery & 1.8 \\
\hline
\end{tabular}




\section{Appendix 2 Reporting quality and risk of bias per journal}

\begin{tabular}{|c|c|c|c|}
\hline Journals & Articles $(n)$ & $\begin{array}{l}\text { Reporting quality } \\
\text { (number per category) }\end{array}$ & $\begin{array}{l}\text { Risk of bias } \\
\text { (number per category) }\end{array}$ \\
\hline \multicolumn{4}{|l|}{ Otolaryngology journals } \\
\hline - Journal of the Association for Research in Otolaryngology & 0 & - & - \\
\hline - Hearing Research & 2 & 2 high & 2 high \\
\hline - Ear and Hearing & 4 & $\begin{array}{l}2 \text { moderate } \\
2 \text { high }\end{array}$ & 4 high \\
\hline - Audiology and Neurotology & 7 & $\begin{array}{l}6 \text { moderate } \\
1 \text { high }\end{array}$ & 7 high \\
\hline - Head \& Neck & 60 & $\begin{array}{l}36 \text { moderate } \\
24 \text { high }\end{array}$ & $\begin{array}{l}1 \text { moderate } \\
59 \text { high }\end{array}$ \\
\hline - Clinical Otolaryngology & 15 & $\begin{array}{l}10 \text { moderate } \\
5 \text { high }\end{array}$ & $\begin{array}{l}1 \text { moderate } \\
14 \text { high }\end{array}$ \\
\hline - The American Journal of Rhinology \& Allergy & 28 & $\begin{array}{l}13 \text { moderate } \\
15 \text { high }\end{array}$ & $\begin{array}{l}1 \text { low } \\
1 \text { moderate } \\
26 \text { high }\end{array}$ \\
\hline - The Laryngoscope & 90 & $\begin{array}{l}2 \text { low } \\
60 \text { moderate } \\
28 \text { high }\end{array}$ & $\begin{array}{l}3 \text { low } \\
2 \text { moderate } \\
85 \text { high }\end{array}$ \\
\hline - Otology \& Neurotology & 56 & $\begin{array}{l}1 \text { low } \\
38 \text { moderate } \\
17 \text { high }\end{array}$ & $\begin{array}{l}1 \text { low } \\
2 \text { moderate } \\
53 \text { high }\end{array}$ \\
\hline $\begin{array}{l}\text { - Current Opinion in Otolaryngology \& Head \& Neck Surgery } \\
\text { Medical journals }\end{array}$ & 0 & - & - \\
\hline - CA: A Cancer Journal for Clinicians & 0 & - & - \\
\hline - The New England Journal of Medicine & 2 & $\begin{array}{l}1 \text { moderate } \\
1 \text { high }\end{array}$ & $\begin{array}{l}1 \text { low } \\
1 \text { high }\end{array}$ \\
\hline - The Lancet & 0 & - & - \\
\hline - JAMA: The Journal of the American Medical Association & 3 & $\begin{array}{l}1 \text { moderate } \\
2 \text { high }\end{array}$ & $\begin{array}{l}1 \text { low } \\
2 \text { high }\end{array}$ \\
\hline - The Lancet Oncology & 6 & 6 high & 1 low 5 moderate \\
\hline - Journal of Clinical Oncology & 16 & $\begin{array}{l}2 \text { moderate } \\
14 \text { high }\end{array}$ & $\begin{array}{l}2 \text { moderate } \\
14 \text { high }\end{array}$ \\
\hline - Annals of Internal Medicine & 3 & 3 high & $\begin{array}{l}1 \text { low } \\
1 \text { moderate } \\
1 \text { high }\end{array}$ \\
\hline - PLOS Medicine & 0 & - & - \\
\hline - The BMJ & 0 & - & - \\
\hline - Journal of the National Cancer Institute & 2 & 2 high & $\begin{array}{l}1 \text { moderate } \\
1 \text { high }\end{array}$ \\
\hline - JAMA Internal Medicine & 1 & 1 high & 1 low \\
\hline - American Journal of Respiratory and Critical Care Medicine & 1 & 1 moderate & 1 high \\
\hline - Journal of Allergy and Clinical Immunology & 12 & $\begin{array}{l}5 \text { moderate } \\
7 \text { high }\end{array}$ & $\begin{array}{l}1 \text { low } \\
1 \text { moderate } \\
10 \text { high }\end{array}$ \\
\hline - Canadian Medical Association Journal & 0 & - & - \\
\hline - Clinical Cancer Research & 7 & $\begin{array}{l}1 \text { moderate } \\
6 \text { high }\end{array}$ & 7 high \\
\hline - Annals of Surgery & 0 & - & - \\
\hline - The American Journal of Clinical Nutrition & 2 & 2 high & $\begin{array}{l}1 \text { low } \\
1 \text { high }\end{array}$ \\
\hline - Annals of Oncology & 18 & $\begin{array}{c}6 \text { moderate } \\
12 \text { high }\end{array}$ & $\begin{array}{l}1 \text { low } \\
17 \text { high }\end{array}$ \\
\hline - Allergy & 3 & $\begin{array}{l}2 \text { moderate } \\
1 \text { high }\end{array}$ & 3 high \\
\hline - BMC Medicine & 0 & - & - \\
\hline
\end{tabular}

Address for correspondence:

Dr Nina M Kaper,

Department of Otorhinolaryngology and Head and Neck Surgery,

Brain Center Rudolf Magnus,

University Medical Center Utrecht,

Heidelberglaan 100, PO Box 85500, 3508 GA Utrecht,

Utrecht, The Netherlands
Fax: +31 (0)30 2541922

E-mail: ninakaper@hotmail.com

Dr N M Kaper takes responsibility for the integrity of the content of the paper

Competing interests: None declared 